\title{
DETERMINANTES DO COMÉRCIO BRASIL-CHINA DE COMMODITIES E PRODUTOS INDUSTRIAIS: UMA APLICAÇÃO VECM
}

\author{
Caio Marcos Mortatti * \\ Sílvia Helena Galvão de Miranda ${ }^{\dagger}$ \\ Mirian Rumenos Piedade Bacchi ${ }^{\ddagger}$
}

\begin{abstract}
Resumo
O objetivo principal deste trabalho é analisar as variáveis que determinam o comércio entre Brasil-China, considerando uma classificação proposta para commodities agrícolas, minerais e produtos industriais. Adotouse um modelo de auto-regressão vetorial com correção de erro (VECM), através da decomposição de Bernanke. O período de análise compreendeu de 1995 a 2008. Os resultados indicam um alto poder explanatório da variável renda sobre a dinâmica das exportações para as três categorias avaliadas. Adicionalmente, a utilização da capacidade instalada apresentou coeficientes consistentes, mostrando que tal variável conseguiu captar corretamente os efeitos da demanda interna sobre as exportações.
\end{abstract}

Palavras-chave: Brasil, China, commodities, VECM, produtos industriais.

\begin{abstract}
The main objective of this work is to analyze the variables that determine the bilateral trade between Brazil and China, considering a classification proposed for the agricultural and mineral commodities and processed products. A vector-auto regression model with error correction (VECM) was adopted, through the Bernanke decomposition. The analysis period was from 1995 to 2008 . The results indicate a high explanatory power of the income variable on the exports dynamics. In addition, the capacity utilization had consistent coefficients for all models estimated showing that this variable was able to capture correctly the effects of the domestic demand on exports.
\end{abstract}

Palavras-chave: Brazil, China, commodities, VECM, processed products.

JEL classification: C32, Q17

\footnotetext{
${ }^{*}$ Mestrando em Economia Aplicada pela FEA Ribeirão Preto da Universidade de São Paulo. Email: caio.mortatti@fearp.usp.br. O autor agradece o apoio financeiro da FAPESP.

† ESALQ, Universidade de São Paulo. Email: smiranda@esalq.usp.br

‡ ESALQ, Universidade de São Paulo. Email: mrpbacch@esalq.usp.br
} 


\section{Introdução}

O desempenho do comércio exterior brasileiro nos últimos anos é marcado, entre outros elementos, por uma crescente participação dos chamados "novos mercados", entendidos como os países que estão fora do eixo tradicional da União Européia, Nafta, América Latina e Japão. Entre esses "novos mercados" a China se destaca, desempenhando um papel primordial no comércio exterior brasileiro, alcançando em 2009 a classificação de maior parceiro do Brasil.

O comércio exterior brasileiro ainda é significativamente concentrado em um número limitado de países. Em 2008, a União Européia e os Estados Unidos foram responsáveis por 37,29\% das exportações brasileiras e por 35,69\% das importações de acordo com os dados de Comércio de Commodities das Nações Unidas (Comtrade, 2010).

Brasil e China mantiveram uma relação comércio informal desde a criação da República da China em 1949. Nos anos 50, o fluxo comercial era praticamente inexpressivo, cerca de US\$ 8 milhões Miranda et al. (2007). Nos anos 90, houve um boom do comércio bilateral, comparado com as décadas passadas e a China, que era a quarta no destino das exportações brasileiras, pulou para a terceira posição desde 2002, atrás apenas dos Estados Unidos e da Argentina ${ }^{1}$. Em 2006, com o amadurecimento das relações comerciais entre o Brasil e a China, a corrente de comércio entre os dois países ultrapassou os US\$ 16,39 bilhões (US\$23,37 bilhões em 2007). No ano de 2008 a China ultrapassou a Argentina e tornou-se o segundo maior parceiro comercial do Brasil, adicionalmente, seguindo nessa trajetória, no ano seguinte em 2009 a China ultrapassou os Estados Unidos e tornou-se o principal parceiro comercial brasileiro, segundo os dados do Ministério do Desenvolvimento, Indústria e Comércio Exterior (MDIC, 2009).

As relações comerciais sino-brasileiras estão, inevitavelmente, inseridas no contexto de mudanças globais, apresentando objetivos comuns de sustentação de projetos econômicos de desenvolvimento. Assim, torna-se importante a avaliação dos fatores que determinam o padrão de comércio entre os dois países em conjunto, pois ambos deverão implementar suas fórmulas políticas destinadas a enfrentar a realidade atual, partindo da situação de fato que os caracteriza: duas verdadeiras pan-regiões territorialmente, mas desafiadas a desenvolver-se para atingir padrões mais altos de riqueza.

\section{Objetivos}

O presente trabalho tem como objetivo principal analisar o comércio bilateral Brasil-China de modo a identificar os seus fatores determinantes e sua evolução em período recente.

Como objetivos específicos propõem-se a:

1. Analisar a pauta dos principais produtos comercializados entre Brasil e China, bem como sumarizar as principais barreiras tarifárias e nãotarifárias entre os dois países; e

2. Identificar as principais variáveis relevantes para modelar tal comércio, e adicionalmente, verificar as diferenças, inclusive em termos de efeitos

\footnotetext{
${ }^{1}$ Considerando União Européia desagregada em seus países membros.
} 
das variáveis determinantes do comércio, quando se analisam categorias distintas de produtos.

\section{Comércio Brasil-China}

Na última década o comércio bilateral Brasil-China evoluiu consideravelmente. Entre o período de 1984 a 2008, as importações brasileiras de produtos chineses aumentaram, em média, $16,57 \%$ ao ano, enquanto as exportações, $15,43 \%$ ao ano.

No período de 1999 até 2003, a China foi responsável por 15,4\% do destino total das exportações brasileiras Miranda et al. (2007). Diversos fatores devem ter contribuído para essa tendência. Em 1999, houve a adoção da taxa de câmbio "flexível suja" pelo Brasil, e, em 2001, a China ingressou como paísmembro da Organização Mundial do Comércio (OMC). De fato, nota-se um crescimento significativo das exportações brasileiras para a China a partir de 2001. Vale ressaltar que em período mais recente, a velocidade de crescimento das importações brasileiras da China com relação à velocidade das exportações tem aumentado, ou seja, o Brasil passou a importar mais produtos da China do que exportar para esse país, conforme evidenciado na Figura 1.

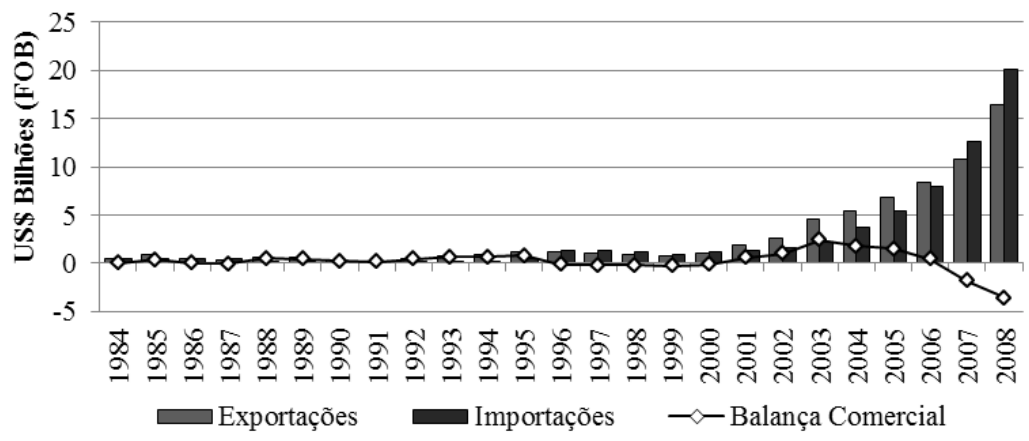

Fonte: Elaborado pelos autores, com base nos dados do WITS/Comtrade (2009).

Figura 1: Balança Comercial Brasil-China de 1984 a 2008, US\$ Bilhões FOB.

Uma análise das principais mercadorias transacionadas entre as economias do Brasil e da China aponta que nos primórdios da década de 1980-90 o Brasil exportava para a China principalmente produtos manufaturados e importava basicamente matérias-primas agrícolas, minerais e metais e seus derivados.

Contudo, ao longo dos anos este quadro foi se alterando, tanto em função da crescente necessidade chinesa de bens de consumo e do processo ainda em andamento de urbanização, como pela melhoria da sua economia, que cada vez mais se industrializava. Como resultado, observa-se que nos últimos anos o Brasil tornou-se um importador de equipamentos industrializados, manufaturados e um exportador de commodities, como grãos de soja e minério de ferro (Figura 2).

A composição das exportações chinesas para o Brasil inclui uma grande parcela de produtos industrializados, em sua grande maioria produtos de alto 


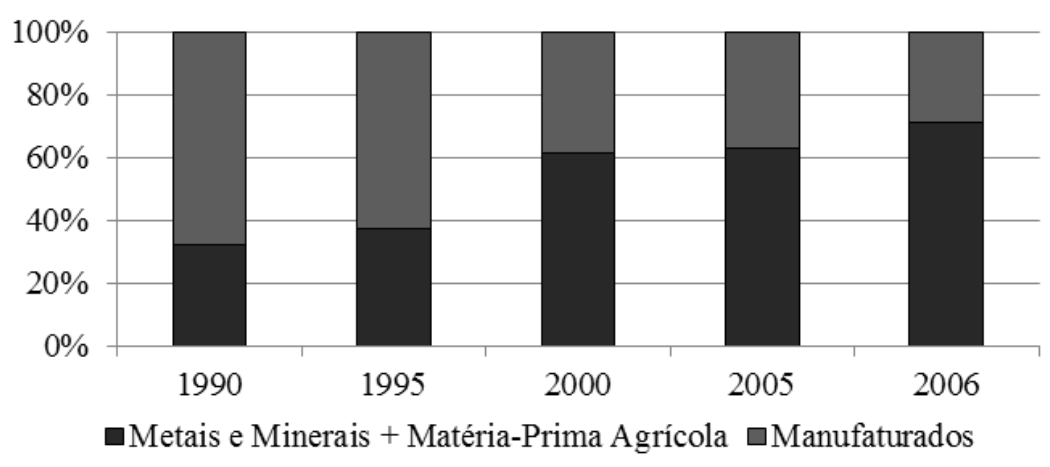

Fonte: Elaborado pelos autores, com base nos dados do WITS/Comtrade (2009).

Figura 2: Categorias exportadas pelo Brasil para a China, período selecionado (valores em $\%$ sobre valor).

valor agregado, sendo que, em 2007, cerca de 68,32\% dessas exportações compreenderam máquinas, aparelhos elétricos, materiais têxteis, produtos de indústrias químicas ou das indústrias conexas.

Já no perfil de exportação do Brasil para a China constata-se exatamente o contrário, com predominância de produtos de baixo valor agregado, sendo que, em 2007 , cerca de $71,17 \%$ dos produtos foram matérias-primas vegetais e minerais (Comtrade 2008).

Ainda no que se diz respeito a essa composição, analisando a pauta em seu maior nível de detalhamento, ou seja, na definição pelo HS2002 a 6-dígitos, em 2007 observa-se uma concentração ainda maior, pautada em um número muito pequeno de itens.

No caso das exportações brasileiras para a China, há o predomínio de dois produtos em particular, minério de ferro ${ }^{2}$ e soja em grão, respectivamente, com $34,55 \%$ e $26,37 \%$, de participação na pauta total, totalizando $60,92 \%$ dessas exportações em 2007 (Tabela 1). É valido ressaltar que os dez principais produtos exportados pelo Brasil para a China representaram $83,49 \%$ de todos os bens que o Brasil exportou para esse país em 2007.

Ao utilizar valor agregado como base de análise, os produtos básicos representaram $73,8 \%$ da pauta exportadora brasileira para a China, seguidos dos semimanufaturados, com $18 \%$, e dos manufaturados, com $8,2 \%$.

Com relação às barreiras tarifárias do comércio sino-brasileiro, nota-se que os 10 principais produtos exportados pelo Brasil não são objetos de elevadas tarifas de importação por parte da China. Entre os dez principais produtos, o tabaco total ou parcialmente destalado (HS 24.01.20) é o produto sobre o qual incide o maior imposto de importação $(10 \%)$, seguido pelo óleo de soja bruto, mesmo degomado (HS 15.07.10) com $9 \%$ e pelos couros e peles curtidos, plena flor, não divididos etc. (HS 41.04.11) que são alvo de uma tarifa de $6,33 \%$.

No caso das importações brasileiras da China há um evidente predomínio de produtos de alto valor agregado de indústrias conexas de alta tecnologia. Num âmbito geral os produtos consistem em máquinas, aparelhos de telefonia, de automação, têxteis, vestuário, coque etc.; e são menos concentradas em

\footnotetext{
${ }^{2}$ Somatório HS 26.01.11 e 26.01.12.
} 
Tabela 1: Ranking dos principais produtos exportados pelo Brasil para a China e sua participação percentual na receita total dessa pauta em 2007.

\begin{tabular}{|c|c|c|c|}
\hline Ranking & $\operatorname{HS}(2002)^{*}$ & Descrição do Produto & Participação \\
\hline $1^{\mathrm{o}}$ & 26.01 .11 & Minérios de Ferro e seus concentrados & $29,04 \%$ \\
\hline $2^{\circ}$ & 12.01 .00 & Soja em grão & $26,37 \%$ \\
\hline $3^{\circ}$ & 27.09 .00 & $\begin{array}{l}\text { Óleos de Petróleo e obtidos de minerais } \\
\text { betuminosos }\end{array}$ & $7,82 \%$ \\
\hline $4^{\circ}$ & 26.01 .12 & $\begin{array}{l}\text { Minérios de Ferro e seus concentrados, } \\
\text { aglomerados }\end{array}$ & $5,51 \%$ \\
\hline $5^{\circ}$ & 47.03 .29 & $\begin{array}{l}\text { Pastas químicas de madeira de não coní- } \\
\text { feras }\end{array}$ & $3,59 \%$ \\
\hline $6^{\circ}$ & 15.07.10 & Óleo de soja bruto, mesmo degomado & $2,89 \%$ \\
\hline $7^{\circ}$ & 24.01 .20 & Tabaco total ou parcialmente destalado & $2,52 \%$ \\
\hline $8^{\circ}$ & 41.04 .11 & $\begin{array}{l}\text { Couros e peles curtidos, plena flor, não } \\
\text { divididos; etc }\end{array}$ & $1,97 \%$ \\
\hline $9^{\circ}$ & 72.02 .93 & Ferroligas, ferronióbio & $1,92 \%$ \\
\hline $10^{\circ}$ & 74.03 .11 & Cobre refinado, cátodos e seus elementos & $1,86 \%$ \\
\hline Top 10 & & & $83,49 \%$ \\
\hline
\end{tabular}

número de itens tarifários, sendo que os dez principais produtos somaram, em 2007, cerca de 27,26\% do total dessa pauta comercial (Tabela 2).

Tendo como base de classificação os bens em categorias agregadas, a importação brasileira de produtos chineses, no ano de 2007, foi composta de cerca de $96,7 \%$ de bens manufaturados, $2,5 \%$ de básicos e $0,8 \%$ de semimanufaturados.

Já com relação às barreiras tarifárias aplicadas pelo Brasil aos dez principais produtos importados da China, pode-se observar uma incidência relativamente maior de tarifas do que nas importações da China de produtos brasileiros, tanto em termos de frequência de incidência quanto dos níveis das alíquotas aplicadas.

O produto alvo de maior tarifa efetiva aplicada, entre os dez principais produtos exportados da China para o Brasil, são os triciclos, patinetes e outros brinquedos semelhantes de rodas (HS 95.03.90), com $20 \%$.

\subsection{Barreiras Tarifárias e Não-Tarifárias}

A seguir, serão descritas sumariamente algumas das principais barreiras comerciais aplicadas pela China ao comércio internacional, procurando dar ênfase aos setores, produtos, normas e temas que mais têm impacto sobre os produtos brasileiros.

No âmbito geral, a entrada da China na OMC, em 2001, fez com que o país se comprometesse a implementar reformas para reduzir as barreiras ao comércio e a facilitar acesso a seu mercado. Em consequência, a China revo- 
Tabela 2: Ranking dos principais produtos importados pelo Brasil da China e sua participação percentual na receita total dessa pauta em 2007.

\begin{tabular}{|c|c|c|c|}
\hline Ranking & HS $(2002)^{*}$ & Descrição do Produto & Participação \\
\hline $1^{\mathrm{o}}$ & 85.17 .90 & Partes de aparelhos de telefonia & $6,59 \%$ \\
\hline $2^{\circ}$ & 90.13 .80 & $\begin{array}{l}\text { Outros dispositivos e instrumentos de } \\
\text { cristais líquidos }\end{array}$ & $4,03 \%$ \\
\hline $3^{\circ}$ & 84.73 .30 & $\begin{array}{l}\text { Partes e acessórios das máquinas da po- } \\
\text { sição } 84.71\end{array}$ & $3,74 \%$ \\
\hline $4^{\circ}$ & 85.42 .21 & $\begin{array}{l}\text { Circuitos integrados eletrônicos digi- } \\
\text { tais }\end{array}$ & $2,64 \%$ \\
\hline $5^{\circ}$ & 85.29 .90 & $\begin{array}{l}\text { Outras partes de aparelhos das posições } \\
85.25 \text { a } 85.28 \text {. }\end{array}$ & $1,89 \%$ \\
\hline $6^{\circ}$ & 84.71 .70 & $\begin{array}{l}\text { Máquinas automáticas com unidades } \\
\text { de memória }\end{array}$ & $1,86 \%$ \\
\hline $7^{\circ}$ & 85.17 .80 & Outros aparelhos telefônicos & $1,86 \%$ \\
\hline $8^{\circ}$ & 27.04 .00 & $\begin{array}{l}\text { Coques e semicoques mesmo aglomera- } \\
\text { dos }\end{array}$ & $1,63 \%$ \\
\hline $9^{\circ}$ & 95.03 .90 & $\begin{array}{l}\text { Triciclos, patinetes e outros brinquedos } \\
\text { de rodas; }\end{array}$ & $1,52 \%$ \\
\hline $10^{\circ}$ & 84.43 .59 & $\begin{array}{l}\text { Outras Máquinas e aparelhos de im- } \\
\text { pressão }\end{array}$ & $1,48 \%$ \\
\hline
\end{tabular}

\begin{tabular}{lc}
\hline Top 10 & $27,26 \%$ \\
\hline${ }^{*}$ Sistema Harmonizado de Designação e Codificação de Mercadorias de 2002 (HS 2002, \\
6dígitos)
\end{tabular}

Fonte: Elaborado pelos autores com base nos dados do WITS (COMTRADE, 2008).

gou e alterou várias leis e regulamentos e estabeleceu cronogramas de redução e eliminação de medidas protecionistas.

Nesse contexto, a China foi obrigada a eliminar o sistema de quotas e aplicar normas internacionais para testes básicos, remover exigências de conteúdo nacional e dar transparência a regimes de licenciamento e registros. O país asiático fez progressos também com reformas, revisões de regulamentos e exigência de conteúdo local (MDIC, 2008). Como exemplo pode-se citar a redução da tarifa média aplicada (AHS) incidente sobre a soja mesmo triturada (HS 12.01 .00 ) de $140 \%$ para 2,4\% (WITS/TRAINS, 2008).

De acordo com a UNCTAD (1998), havia 69 picos tarifários na China, dentre os quais alguns produtos de interesse ao agronegócio brasileiro como a soja, por exemplo. Ademais, é válido citar também as barreiras não-tarifárias às importações impostas pela China, como quotas, licenças para importar, políticas de substituição de importações, além de certificações restritivas e padrões de quarentena. De acordo com a Embaixada da República Popular da China no Brasil em setembro de 2007 a China notificou à OMC a adoção de 63 barreiras técnicas comerciais (BTC) para proteger a saúde pública e o meio ambiente no país.

A atual legislação chinesa referente a medidas sanitárias e fitossanitárias pode ser resumida, de acordo com o Ministério do Desenvolvimento, Indústria e Comércio Exterior (MDIC, 2008), nas seguintes leis e regulamentos: (i) 
Lei sobre a Quarentena de Entrada e Saída de Fauna e Flora; (ii) Lei sobre a Higiene Alimentar; (iii) Lei sobre a Prevenção de Enfermidades Animais; (iv) Quarentena fitossanitária; (v) Lei sobre Inspeção de Mercadorias de Importação e de Exportação; e (vi) Lei sobre Saúde em Fronteira e Quarentena.

Algumas consultas de países junto à OMC envolvendo a China dizem respeito ao uso dos regulamentos sanitários e fitossanitários como barreiras comerciais, visto que eles não são apoiados em evidências científicas sólidas. Entretanto, apesar dessas mudanças, muitas práticas continuam a distorcer o comércio exterior chinês. A quarentena, por exemplo, imposta pela aduana, pode atrasar navios com produtos agrícolas não chineses. Ela se baseia em regulamentos sanitários e fitossanitários elaborados a partir de bases científicas dispersas e regulamentos questionáveis sobre a importação de commodities agrícolas (MDIC, 2008).

Além dessas descritas acima, destaca-se também que, desde 1997, a China pode impor direitos antidumping e medidas compensatórias às importações que ameacem ou causem danos à indústria doméstica de acordo com o Departamento de Negociações Internacionais do MDIC.

Cabe ressaltar também a influência das empresas estatais chinesas no comércio, principalmente de commodities agrícolas, através da China National Cereals, Oils and Foodstuffs Import and Export Company (COFCO), que tem marcado o cenário da política agrícola da China por diversos anos. Dada a prevalência que a China tem nos mercados mundiais, não foi surpresa de que tal influência foi um dos principais aspectos a serem questionados para a entrada do país na OMC. Apesar das tentativas de estabelecer no protocolo de acesso da OMC limitações à interferência estatal no comércio, a COFCO ainda tem um potencial significativo de controle sobre ambas as exportações e importações de diversas commodities de acordo com McCorriston \& MacLaren (2007).

\section{Metodologia}

\subsection{Modelos de Comércio Internacional}

O uso de funções de importação e exportação para averiguar o comportamento do comércio entre os países busca compreender os efeitos de alterações das políticas macroeconômicas e comerciais das nações sobre o comércio entre elas. $\mathrm{Na}$ literatura, encontram-se trabalhos bem fundamentados que buscaram teorizar sobre as especificações das equações de comércio internacional.

Utiliza-se com frequência a construção de modelos para produtos específicos ou para o agregado da pauta. Entre os trabalhos que tratam da estimação dessas funções podem ser citados, destacadamente: Leamer \& Stern (1970), Goldstein \& Khan (1978), Pinto (1980), Braga \& Markwald (1983), Zini (1988), Castro \& Cavalcanti (1997), Cavalcanti \& Ribeiro (1998), Carvalho \& Negri (2002), Miranda (2001) e Barros et al. (2002).

Em geral, segundo Leamer \& Stern (1970) há duas formulações teóricas básicas para o cenário geral que especifica as equações de comércio exterior. A primeira corresponde ao modelo para um país pequeno, em que o volume de comércio do país depende de suas condições internas, assumindo que se defronta com uma função de demanda por suas exportações infinitamente preço-elástica. 
Cabe mencionar que a hipótese da demanda por exportações infinitamente elástica também sofre críticas, particularmente quando se considera que existem restrições ao comércio limitando o acesso dos fornecedores externos aos mercados domésticos. Este é um ponto bastante relevante quando se considera, por exemplo, o mercado de produtos do agronegócio, de maior valor agregado, ou de produtos com alto grau de protecionismo.

Zini (1988) comenta que as funções de demanda e de oferta de exportação podem ser especificadas assumindo que os produtos importados não são substitutos perfeitos para os bens domésticos. Isso permite estimar as elasticidades-preço finitas para a oferta e demanda por exportação. O autor explica que o modelo de substitutos perfeitos é adequado quando se tratam de mercados de bens homogêneos. Assim, a segunda abordagem apresentada pelo autor é a do modelo competitivo de dois países, no qual se abandonam as hipóteses de elasticidades infinitas.

Zini (1988) estimou elasticidades de exportação e de importação para o Brasil, de modo consistente, por grupos de bens, em um trabalho que se tornou referência nesse tema. O autor identifica que a oferta de exportação brasileira para o comércio do Brasil é preço-elástica e diminui com o aumento da capacidade instalada no país, para o período analisado de 1970 a 1986 . Já a demanda externa por exportações e a demanda interna por importações mostraram baixas elasticidades-preço e altas elasticidades-renda, para o mesmo período, para produtos agrícolas, minerais e industrializados.

Outro estudo de destaque foi realizado por Castro \& Cavalcanti (1997), em que foram estimadas equações de importação e exportação totais por fator agregado e desagregadas por categoria de uso, para o Brasil. Os autores utilizaram valores anuais (em dólar), o que se diferencia de outros trabalhos que optaram pela utilização de índices de preços e quantidade. Consideraram o período entre 1955 e 1995. Após a constatação da não-estacionariedade das séries analisadas no trabalho, os autores realizaram um teste de cointegração entre as variáveis e ajustaram o modelo através de um mecanismo de correção de erros. Os resultados revelaram que depreciações na taxa de câmbio real são mais eficientes para uma redução no déficit comercial do que variações em outras variáveis macroeconômicas.

Carvalho \& Negri (2002) estimaram as equações para os quantum de produtos agropecuários importados e exportados pelo Brasil, trimestralmente, conclu-indo-se que as importações de produtos agropecuários se mostraram altamente dependentes da taxa de câmbio real e da taxa de utilização da capacidade doméstica instalada. Já as exportações brasileiras desses produtos foram influenciadas basicamente pelo nível de atividade mundial e, em menor grau, pela taxa de câmbio real.

Partindo da abordagem de excedentes de oferta e de demanda, Miranda (2001), estimou as equações de vendas externas de carne bovina brasileira. A autora analisou o comércio com a União Européia e com os Estados Unidos, buscando identificar os efeitos de barreiras não-tarifárias sobre o comércio do produto. Novamente, a taxa de câmbio real mostrou-se uma variável bastante relevante para influenciar os volumes exportados.

No trabalho de Barros et al. (2002) foram estimadas as funções de oferta de exportação de produtos agropecuários para o Brasil, considerado o período de 1992 a 2000. Os autores apresentaram um modelo teórico, baseado no trabalho de Miranda (2001), especificando modelos econométricos, ajustados para 
diferentes produtos, nos quais a equação de oferta de exportação é derivada das funções de oferta e de demanda internas.

Os autores acima referidos atestaram, de modo geral, que os impactos do crescimento da economia brasileira sobre as exportações do agronegócio mostraram-se expressivos, confirmando a impressão de que a contenção do crescimento doméstico contribui para que maiores volumes sejam exportados. A taxa de câmbio mostrou ser também importante fator determinante das exportações do agronegócio brasileiro, sendo as de soja (e seus derivados) e açúcar as mais influenciadas pelo câmbio. Em relação ao preço externo, açúcar e soja são novamente os produtos mais afetados, ao lado de carne industrializada. Os preços domésticos tenderam a refletir o desempenho da produção doméstica em face da demanda interna, e as exportações de açúcar foram as mais sensíveis ao comportamento do mercado interno.

Dessa forma, o modelo de comércio proposto no presente trabalho adotará as especificações de variáveis condicionantes à semelhança de Zini (1988), partindo do modelo econômico proposto originalmente por Miranda (2001) e reproduzido por Barros et al. (2002). Adicionalmente será adotada a metodologia de estimação proposta por Castro \& Cavalcanti (1997). Portanto, o modelo proposto resulta da contribuição de tais autores.

A estimação de funções de exportação para o comércio entre Brasil-China, analisando commodities (agrícolas e minerais) e produtos industriais possibilita compreender melhor os fatores que interferem nas transações e distinguir se seus efeitos são distintos em função de diferentes grupos de produtos. Deste modo, subsidiar a interpretação de possíveis resultados de políticas de incentivos, que promovam alterações nas variáveis condicionantes, permitindo análises prospectivas sobre o comportamento desse comércio bilateral.

\subsection{Banco de dados e descrição das variáveis}

A principal base de dados utilizada é a do World Integrated Trade Solution (WITS), além dos dados do Fundo Monetário Internacional (FMI), do sistema AliceWeb do Ministério do Desenvolvimento, Indústria e Comércio Exterior (MDIC), do Comtrade e do Instituto de Pesquisa Econômica Aplicada (Ipeadata). Os dados de comércio dos dois países são mensais, e o período de análise abrange os anos de 1995 a 2008, totalizando 168 observações temporais para cada variável. Os produtos encontram-se agregados conforme a Nomenclatura Comum do MERCOSUL (NCM).

Foram identificadas algumas agregações distintas entre produtos básicos, industriais e do agronegócio, encontradas na literatura, tais como as classificações internacionais das Nações Unidas, como a Broad Economic Category (BEC) e a Standard International Trade Classification (SITC), também a classificação do governo dos Estados Unidos, a Standard Industrial Classification (SIC), além da classificação da Organização Mundial do Comércio para os produtos do agronegócio. Neste trabalho, a proposta contida na Tabela 3, resulta da agregação com base nos principais aspectos de classificação internacional de mercadorias.

As exportações brasileiras de produtos agrícolas, industriais e minerais, em quantum ( $Q A, Q I$ e $Q M$ ), foram obtidas através do sistema AliceWeb (2009). Foram coletados dados para os capítulos de cada uma das categorias, numa série mensal de jan-1995 até dez-2008. 
Tabela 3: Classificação dos produtos da NCM em grupos: Agrícolas, Minerais e Industriais.

\begin{tabular}{ccc}
\hline No da Seção & Capítulos (NCM) & Classificação \\
\hline I ao IV & 1 ao 24 & Agrícolas \\
V & 25 ao 27 & Minerais \\
VI ao XIII & 28 ao 70 & Industriais \\
XIV ao XV & 71 ao 83 & Minerais \\
XVI ao XXI & 84 ao 99 & Industriais \\
\hline Fonte: Elaborado pelos autores com base na agregação da \\
NCM, em adaptação das classificações internacionais: da \\
OMC para o agronegócio, das Nações Unidas (BEC e SITC) \\
e do governo dos Estados Unidos (SIC).
\end{tabular}

Para a construção dos índices de preço relativos de exportação para agrícolas, minerais e industriais ( $P R A, P R M$ e $P R I)$ foram utilizados dados de índices de preços obtidos junto à base de dados do Ipeadata e junto ao FMI, para Brasil e mundo, respectivamente. Os índices $P R A, P R M$ e $P R I$ foram calculados pela razão entre os índices de preços externos e internos.

Para a variável renda $(Y)$, foi utilizado como proxy o valor total das importações chinesas, obtida dos dados das Nações Unidas (Comtrade, 2009). A taxa de câmbio real R\$/Yuan (TX) foi calculada pela taxa de câmbio nominal " $e$ " e pela relação dos índices de preços internacionais de cada país, tendo como referência a base de dados do Ipeadata.

O PIB potencial foi calculado segundo o método utilizado pelo Banco Central (BACEN), baseado em técnicas estatísticas para a determinação da tendência do produto, tal técnica consiste no uso do filtro Hodrick-Prescott das séries temporais sobre a série trimestral do PIB real do Brasil, tendo como base o sistema de Contas Nacionais do IBGE. Dessa forma, o índice de utilização da capacidade instalada $(Y)$ foi considerado como a relação entre o PIB real e o Potencial. Este indicador para ciclos domésticos é adotado para captar os efeitos dos ciclos da demanda interna sobre a oferta de exportação.

Todas as variáveis foram transformadas nos logaritmos dos valores observados.

\subsection{Testes e procedimentos de estimação}

Para a avaliação das condições de estacionariedade das séries temporais serão aplicados testes robustos de identificação, superando os problemas de baixo poder e distorção de tamanho dos tradicionais testes de Dickey-Fuller Aumentado (ADF), Phillips-Perron (PP) e Kwiatkowski, Phillips, Schmidt e Shin (KPSS), amplamente discutidos na literatura.

O primeiro, desenvolvido a partir das especificações ADF, e que permite um estudo adequado da presença de componentes deterministas, será o teste ERS ou DF-GLS de Elliot et al. (1996) que propõe uma modificação simples ao aplicar o ADF à série temporal previamente filtrada de seus componentes deterministas.

O segundo teste, proposto por Perron \& Ng (1996) e Ng \& Perron (2001), segue a metodologia não-paramétrica dos testes PP (Phillips-Perron), em que a matriz de variância dos estimadores dos parâmetros da equação de teste é consistente com heterocedasticidade e autocorrelação. Os autores propõem 
tratar os problemas associados aos testes usuais construindo estatísticas de testes para a série sem os componentes deterministas.

Adicionalmente, será aplicado o teste de Dickey \& Pantula (1987) que tem como principal característica analisar a existência de mais de uma raiz unitária. No presente trabalho, será desenvolvido o teste com o intuito de checar a existência de no máximo duas raízes unitárias. O teste é aplicado de forma sequencial, primeiramente testa-se a hipótese da presença de duas raízes unitárias. Se a hipótese for rejeitada, passa-se para a segunda etapa, na qual é testada a presença de uma raiz unitária contra estacionariedade. Rejeitada a hipótese nula, conclui-se que a série é estacionária, caso contrário a série é $I(1)$.

Os testes convencionais de raiz unitária pressupõem, implicitamente, séries temporais sem sazonalidade ou com padrão uniforme de mudanças sazonais. No entanto, flutuações de caráter aleatório nos componentes sazonais podem estar presentes e contribuir para a não rejeição da hipótese nula de raiz unitária. Esse problema tem sido, às vezes, equacionado por meio de mudanças na equação de teste de forma a incorporar os efeitos da sazonalidade Hylleberg et al. (1990). Diante dessa possibilidade, foi realizado o teste DHF para raiz unitária sazonal. Os valores críticos da estatística relevante, $\tau_{\mu d}$, foram obtidos em Dickey et al. (1984).

Sendo as variáveis em $\mathbf{X}$ (vetor que representa as variáveis do sistema), integradas, ou seja, variáveis que apresentam tendência estocástica (o caso mais comum é aquele em que as séries possuem uma raiz unitária), podem existir até $\mathrm{N}-1$ relações de longo prazo entre elas (sendo $\mathrm{N}$ o número de equações do sistema). No caso de existir tais relações, ou seja, existir cointegração entre as variáveis, termo(s) de correção de erro(s) devem ser incorporados ao modelo ajustado com as séries nas diferenças para evitar erros de especificação. Para a análise de cointegração, parte-se de um Vetor Auto-regressivo (VAR) de ordem $k$ :

$$
\mathbf{X}_{t}=\sum_{i=1}^{k} \lambda_{i} \mathbf{X}_{t-i}+\mu_{0}+\mu_{1} t+\epsilon_{t}
$$

onde $\epsilon_{t} \sim \operatorname{Niid}(0, \Sigma)$, ou seja, os resíduos do VAR devem ser independentes e normalmente distribuídos. Porém, para a validade assintótica das distribuições, basta que os resíduos sejam ruídos brancos $\left(\sum=\delta^{2} I\right)$. A adequada especificação do VAR foi, então, a segunda etapa do trabalho empírico (a primeira foi a verificação da ordem de integração), que utiliza critérios de informação para a seleção da defasagem adequada e testes específicos para a presença de tendência determinista, bem como testes de estabilidade do sistema.

Na presença de séries temporais com raiz unitária (tendência estocástica), o teste de cointegração é feito considerando o VAR adequadamente reparametrizado, representado por:

$$
\Delta \mathbf{X}_{t}=\mu_{0}+\mu_{1} t+\Pi_{k} \mathbf{X}_{t-1}+\sum_{i=1}^{k-1} \Gamma_{i} \Delta \mathbf{X}_{t-1}+\epsilon_{t}
$$

A análise de cointegração, proposta por Johannsen (1991), é realizada, então, por meio de testes sobre o posto da matriz de coeficientes das variáveis em nível defasadas de um período, $\Pi$, que representa as propriedades de longo prazo do sistema, enquanto que $\Gamma_{i}$ com $i=1, \ldots, k-1$, representam o comportamento dinâmico de curto prazo, sendo $k$ a ordem do modelo auto-regressivo. 
Para testar a existência e o número de vetores cointegrados, Johannsen (1991) propõe a utilização de duas estatísticas, a do traço, mais robusta na ausência de normalidade e a do máximo autovalor.

A matriz $\Pi$ pode ser decomposta em duas matrizes: uma com os coeficientes que expressam a velocidade de ajustamento dos desvios do equilíbrio de longo prazo e outra representada pelos vetores de cointegração, relacionados às raízes características diferentes de zero, que se constituem nos termos de correção de erro.

Em função dos resultados obtidos nos testes de integração e cointegração, o modelo econômico proposto a seguir foi estimado pela metodologia de autoregressão vetorial com mecanismo de correção de erro, usando a decomposição de Bernanke para identificar o modelo estrutural a partir da forma reduzida. Considerou-se a influência da renda, utilização da capacidade instalada, taxa de câmbio e preços relativos sobre o volume de exportação brasileira para a China de cada categoria de produto.

Primeiramente, para cada um dos modelos, são apresentados os coeficientes estimados na matriz de relações contemporâneas entre as variáveis. Posteriormente estima-se a variância do erro de previsão de cada variável. Por fim, mensura-se o efeito (magnitude e sinal) dos choques na renda, na utilização da capacidade instalada, na taxa de câmbio e nos preços relativos, para explicar a determinação da trajetória da exportação. Isso é feito através da construção das funções de respostas a impulso.

Para a realização dos procedimentos estatísticos foi utilizado o software WinRats (Regression Analysis of Time Series), em sua versão 6.2.

\subsection{Modelo Proposto}

O modelo de comércio estimado no presente trabalho é baseado no modelo econômico proposto originalmente por Miranda (2001), em que variáveis de oferta e demanda são consideradas determinantes para o fluxo comercial, já que se assume que este resulta de um excedente de oferta (exportação) ou de demanda (importação). É adotada a metodologia de Auto-Regressão Vetorial com correção de erro (VECM), empregada por Castro \& Cavalcanti (1997). Portanto, o modelo é uma adaptação dos autores mencionados acima. Serão estimados três modelos VECM, sendo um para cada tipo de agregação de produto (agrícolas, industriais e minerais), conforme a Tabela 4.

Tabela 4: Especificação dos modelos estimados.

\begin{tabular}{ccc}
\hline Modelos & Especificação & Variáveis \\
\hline Agrícolas & Modelo 1 & $Q A_{t}, Y_{t}, U_{t}, T X_{t}$ e $P R A_{t}$ \\
Industriais & Modelo 2 & $Q I_{t}, Y_{t}, U_{t}, T X_{t}$ e $P R I_{t}$ \\
Minerais & Modelo 3 & $Q M_{t}, Y_{t}, U_{t}, T X_{t}$ e $P R M_{t}$ \\
\hline
\end{tabular}

Fonte: Elaborado pelos autores.

Onde as variáveis $Q A, Q I$ e $Q M$, representam as exportações em quantum para a China, respectivamente de produtos agrícolas, minerais e industriais. As variáveis $P R A, P R I$ e $P R M$ representam os preços relativos de exportação, respectivamente de cada produto supracitado. A taxa de câmbio real (R\$/Yuan) é representada pela variável TX. O grau de utilização da capaci- 
Tabela 5: Resultados dos testes de raiz unitária.

\begin{tabular}{|c|c|c|c|c|c|}
\hline \multirow{3}{*}{ Variáveis } & \multirow{3}{*}{ Lags } & \multicolumn{4}{|c|}{ Estatística de Teste } \\
\hline & & \multirow[t]{2}{*}{ DF-GLS } & \multirow[t]{2}{*}{ Ng-Perron } & \multicolumn{2}{|c|}{ Dickey-Pantula } \\
\hline & & & & $H_{0}: \rho_{1}=0^{\dagger}$ & $H_{0}: \rho_{2}=0^{\ddagger}$ \\
\hline$Q A$ & 8 & $-1,452$ & $-6,026$ & $-7,267^{*}$ & $-1,767$ \\
\hline$Q M$ & 4 & $-2,125$ & $-10,058$ & $-9,962^{*}$ & $-2,245$ \\
\hline$Q I$ & 2 & $-1,886$ & $-8,383$ & $-9,145^{*}$ & $-1,893$ \\
\hline PRA & 1 & $-1,560$ & $-6,624$ & $-7,351^{*}$ & $-1,604$ \\
\hline$P R M$ & 1 & $-1,091$ & $-4,768$ & $-6,549^{*}$ & $-1,231$ \\
\hline$P R I$ & 1 & $-0,862$ & $-4,167$ & $-5,210^{*}$ & $-0,891$ \\
\hline Y & 6 & $-0,896$ & $-4,295$ & $-5,992^{*}$ & $-0,798$ \\
\hline$T X$ & 2 & $-1,745$ & $-7,810$ & $-8,281^{*}$ & $-1,806$ \\
\hline$U$ & 4 & $-1,327$ & $-5,808$ & $-7,003^{*}$ & $-1,411$ \\
\hline
\end{tabular}

dade instalada, $Y$, representa o índice de ciclos domésticos, e a variável $Y$ é uma proxy para a renda chinesa (importações totais da China).

A hipótese é de que a renda chinesa e a utilização da capacidade instalada da economia brasileira tenham um grau de explicação razoável sobre as exportações brasileiras para a China. Espera-se poder verificar também, nos diferentes modelos, o impacto da taxa de câmbio e dos preços relativos.

\section{Resultados e Discussão}

No caso dos testes de raiz unitária, em nenhum dos testes DF-GLS e Ng-Perron foi possível rejeitar a hipótese nula da presença de raiz unitária, por isso, todas as séries foram tomadas como integradas de ordem 1, ou seja I(1). Adicionalmente, a hipótese nula do resultado do teste de Dickey-Pantula, para a verificação da presença de duas raízes unitárias na série, pode ser rejeitada e a hipótese de uma raiz unitária contra estacionariedade não foi rejeitada, confirmando que as séries são integradas de primeira ordem.

O número de defasagens utilizado em cada teste foi determinado através do Critério de Informação de Akaike Modificado (MAIC), proposto por Ng \& Perron (2001). Logo, os modelos foram ajustados com as variáveis nas primeiras diferenças. A Tabela 5 sumariza tais resultados.

Os resultados dos testes para raízes unitárias sazonais, seguindo metodologia de teste de Dickey et al. (1984) apontaram a não existência de raízes unitárias sazonais nas séries analisadas, pois o valor calculado para a estatística, $\tau_{\mu d}$, foi em módulo maior do que o seu valor tabelado, de modo que a hipótese nula da existência de raiz unitária sazonal pode ser rejeitada.

Os testes de cointegração de Johansen realizados para os modelos especificados (agrícolas, industriais e minerais) indicaram a existência de um vetor cointegrante em cada modelo, de forma que eles foram ajustados com a inclusão de um termo de correção de erro. 
Tabela 6: Estimativa da matriz de coeficientes de relações contemporâneas (Modelo 1).

\begin{tabular}{|c|c|c|c|}
\hline \multicolumn{2}{|c|}{ Relações Contemporâneas } & \multirow[b]{2}{*}{ Coeficientes $^{*}$} & \multirow[b]{2}{*}{ Valor $t$} \\
\hline De & Sobre & & \\
\hline Renda $(Y)$ & Quant. exportada (QA) & $-1,570$ & $-4,609$ \\
\hline Util. da cap. instalada $(U)$ & Quant. exportada $(Q A)$ & 1,223 & 2,092 \\
\hline Taxa de Câmbio $(T X)$ & Quant. exportada $(\hat{Q} A)$ & $-0,764$ & $-1,771$ \\
\hline Preço Relativo (PRA) & Quant. exportada $(Q A)$ & $-0,344$ & $-1,552$ \\
\hline
\end{tabular}

A escolha da ordem de defasagem dos modelos VAR teve como base os critérios de Akaike e Schwarz, os quais indicaram uma defasagem. Ou seja, todos os modelos foram estimados como $\operatorname{VECM}(1)$.

\subsection{Modelo 1: Produtos agrícolas}

O modelo analisado foi construído com as seguintes variáveis: $Q A, Y, Y, T X$ e PRA tomadas em primeira diferença dos seus logaritmos, além do vetor de correção de erros. A matriz de relações contemporâneas tem seus resultados expostos na Tabela 6. Os sinais dos coeficientes estão de acordo com o esperado, lembrando-se que devem ser analisados com o sinal contrário dos obtidos na estimação. Contudo, o coeficiente mostrou-se não-significativo a $10 \%$ (significativo a $11,10 \%$ ) para o preço relativo e a taxa de câmbio.

Os demais valores mostraram-se significativos, indicando que um aumento de $1 \%$ na renda da China leva a um aumento de $1,57 \%$ na exportação de produtos agrícolas brasileiros para esse país. Com relação à utilização da capacidade instalada brasileira, um aumento exógeno de $1 \%$ nessa variável leva a uma diminuição de 1,22\% na quantidade exportada para a China, verificandose a preferência pelo abastecimento do mercado doméstico nos ciclos de alta da economia. Com relação à taxa de câmbio, desvalorizações na mesma incentivam ao aumento da exportação de produtos agrícolas para a China, porém em menor magnitude do que a dos efeitos das variáveis anteriores.

A seguir são analisadas as decomposições da variância dos erros de previsão, (optou-se por apresentar somente a decomposição da variância da quantidade exportada que é o objeto de análise principal, embora essa decomposição tenha sido realizada também para as demais variáveis). Tal análise permite fazer referência sobre o poder explicativo de cada variável sobre as demais. As decomposições são apresentadas para um período de 12 meses, sumarizadas de 1 a 3, 10 e 12, após o choque, uma vez que nos períodos posteriores a parcela de explicação de cada variável sobre as demais não sofre alterações significativas.

A variável quantidade exportada $(Q A)$ tem cerca de $65 \%$ de sua variância explicada por ela mesma, sendo que $25 \%$ de sua variância são atribuídos a choques nas variáveis renda e utilização da capacidade instalada. É interessante notar que $(Y)$ tem um papel importante no primeiro trimestre, mas logo no segundo tem seu poder explanatório reduzido; o inverso ocorre com a 
Tabela 7: Decomposição histórica da variância do erro de previsão para QA (Modelo 1).

\begin{tabular}{ccrrrrr}
\hline Meses & Desvio-padrão & $\mathrm{Q} A$ & \multicolumn{1}{c}{$Y$} & \multicolumn{1}{c}{$U$} & $T X$ & \multicolumn{1}{c}{$P R A$} \\
\hline 1 & 1,008 & 77,302 & 1,141 & 17,827 & 3,088 & 0,642 \\
2 & 1,160 & 71,657 & 5,090 & 11,961 & 6,677 & 4,615 \\
3 & 1,195 & 68,739 & 9,413 & 10,832 & 6,480 & 4,536 \\
10 & 1,246 & 64,844 & 15,590 & 9,330 & 6,212 & 4,024 \\
12 & 1,247 & 64,784 & 15,685 & 9,307 & 6,209 & 4,015 \\
\hline
\end{tabular}

Fonte: Dados da pesquisa.

renda. Já as variáveis $(Y)$ e $(T X)$ se comportam como variáveis exógenas, pois mais de $92 \%$ de suas variâncias são explicadas por choques delas próprias. As variáveis $(\mathrm{Y})$ e $(P R A)$ também têm um forte comportamento auto-regressivo, sendo que, respectivamente, cerca de $86 \%$ e $78 \%$, de suas variâncias são explicadas por elas mesmas (Tabela 7).

Na Figura 3 pode-se observar as respostas aos choques positivos de cada uma das variáveis do modelo sobre a quantidade exportada, e nos períodos seguintes ao mesmo.

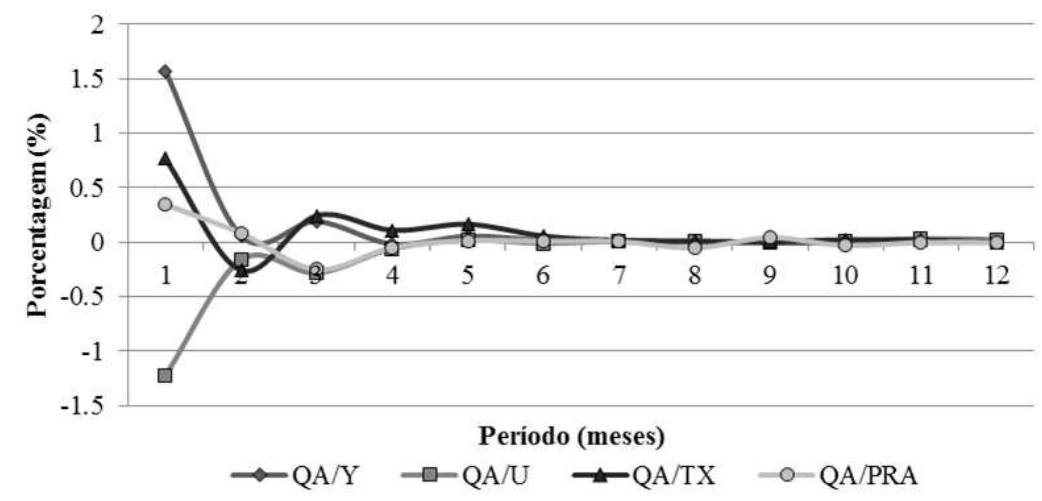

Fonte: Dados da pesquisa.

Figura 3: Função Impulso-Resposta sobre a quantidade exportada de bens agrícolas do Brasil para a China de um impulso nas demais variáveis (Modelo 1).

Verifica-se que a variável $Q A$ responde positivamente a um choque de $1 \%$ na renda, com maior resposta no primeiro período $(1,57 \%)$, sendo que tais choques são positivos para todos os demais períodos, desaparecendo a partir do sexto mês.

Ao submeter a quantidade exportada a um choque positivo de $1 \%$ na utilização da capacidade instalada há uma resposta negativa contemporânea mais do que proporcional no primeiro período de $1,22 \%$, resultado previsto dentro da teoria, pela preferência pelo mercado interno nos ciclos de expansão da economia. Tais choques negativos permanecem até o quinto período, a partir de quando perdem o efeito.

A resposta na quantidade exportada de um aumento de $1 \%$ na taxa de câmbio é mais expressiva no primeiro período (0,76\%), verificando-se que desvalorizações cambiais elevam a quantidade exportada de commodities agrí- 
colas, porém a magnitude de tal efeito é inferior quando comparada com aos efeitos das demais variáveis do sistema, o que reforça os resultados obtidos na análise histórica da decomposição da variância do erro de previsão.

Um pequeno efeito em magnitude pode ser observado quando submetida a quantidade exportada a um choque de $1 \%$ no preço relativo, tal efeito é mais significativo no primeiro período $(0,34 \%)$, se dissipando conforme os períodos vão passando, e a partir do quinto período praticamente desaparecendo. As respostas acumuladas de choques em cada variável sobre a quantidade exportada de produtos agrícolas encontram-se sumarizadas na Figura 4. Assim, um choque positivo de $1 \%$ na renda provoca um aumento imediato de $1,57 \%$ na quantidade exportada, porém o equilíbrio é atingido em torno de 1,86\%, ou seja, o efeito acumulado mais do que compensa a elevação da renda.

Para a utilização da capacidade instalada, há uma diminuição contemporânea direta das exportações agrícolas do Brasil para a China com o aquecimento da economia. No entanto, o efeito acumulado é atingido num patamar ainda menor, em torno de $-1,70 \%$, ilustrando a preferência pelo mercado interno, conforme verificado também por Zini (1988) analisando a pauta comercial brasileira por grupos.

A taxa de câmbio tem, de imediato, certo efeito significativo sobre as exportações agrícolas para a China, porém a elasticidade acumulada se estabiliza em torno de $1,14 \%$, ou seja, o efeito da taxa de câmbio sobre as commodities agrícolas é maior com o passar do tempo, configurando o efeito da "curva J", em que nos primeiros meses logo após a desvalorização da taxa de câmbio há uma piora do saldo comercial com recuperação posterior. Segundo Meade (1988), tal fenômeno emana a partir do fato de que no momento em que ocorre a mudança na taxa de câmbio, os bens já estão sendo comercializados sob contratos que não podem ser "quebrados", e que a finalização de tais transações domina as flutuações comerciais no curto-prazo. Assim, embora uma depreciação tenda a deteriorar o saldo da balança comercial agrícola com a China no curto-prazo, ela tende a elevar tal saldo no longo.

No modelo de produtos agrícolas a única variável que não demonstra diferenças significativas nas elasticidades contemporâneas e acumuladas é a de preço relativo, que se estabiliza próximo a zero a partir do terceiro período.

\subsection{Modelo 2: Bens industriais}

O modelo analisado foi construído com as seguintes variáveis: $Q I, Y, Y, T X$ e PRI tomadas na primeira diferença de seus logaritmos, além do vetor de correção de erros. Seus resultados estão expostos na Tabela 8.

Os sinais dos coeficientes estão de acordo com o esperado, e todos se mostraram significativos a $10 \%^{3}$. Um aumento de $1 \%$ na renda chinesa leva a um aumento de $0,94 \%$ na exportação de produtos industriais do Brasil para a China, menor em magnitude (mais inelástica) se comparada com a elasticidade para os produtos agrícolas. Isto indica um comércio mais renda-elástico da China com o Brasil para produtos básicos do que para produtos industriais, o que era esperado dentro da teoria dada a análise descritiva da pauta.

Com relação à utilização da capacidade instalada brasileira, um aumento exógeno de $1 \%$ nessa variável leva a uma redução de $0,94 \%$ na quantidade ex-

\footnotetext{
${ }^{3}$ Embora os testes " $t$ " não tenham a mesma precisão observada no caso dos modelos de mínimos quadrados, eles, em alguma medida, permitem fazer inferência sobre a significância dos parâmetros estimados.
} 


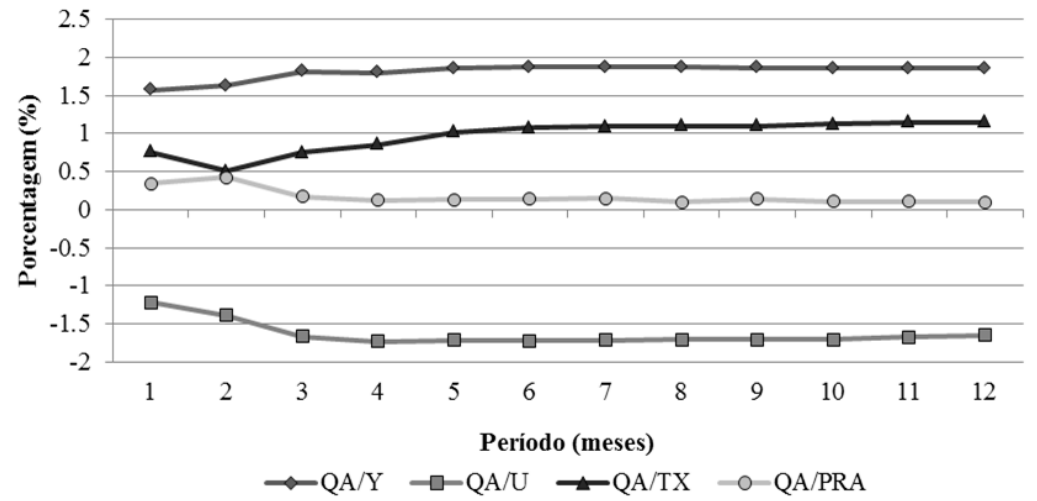

Fonte: Dados da pesquisa.

Figura 4: Evolução dos choques acumulados das exportações de bens agrícolas do Brasil para a China sobre as demais variáveis do modelo (Modelo $1)$.

Tabela 8: Estimativa da matriz de coeficientes de relações contemporâneas (Modelo 2).

\begin{tabular}{|c|c|c|c|}
\hline \multicolumn{2}{|c|}{ Relações Contemporâneas } & \multirow[b]{2}{*}{ Coeficientes $^{*}$} & \multirow[b]{2}{*}{ Valor $t$} \\
\hline De & Sobre & & \\
\hline Renda $(Y)$ & Quant. exportada (QI) & $-0,943$ & $-3,882$ \\
\hline Util. da cap. instalada $(U)$ & Quant. exportada (QI) & 0,941 & 2,181 \\
\hline Taxa de Câmbio (TX) & Quant. exportada (QI) & $-1,315$ & $-1,774$ \\
\hline Preço Relativo $(P R I)$ & Quant. exportada (QI) & $-0,329$ & $-2,866$ \\
\hline
\end{tabular}

portada de bens industriais contemporaneamente. Tal hipótese de que quando o mercado interno se aquece, a oferta de produtos industrializados para exportação cai, não pode ser rejeitada, à semelhança dos resultados obtidos por Zini (1988) para o comércio como um todo.

Com relação à taxa de câmbio, desvalorizações na mesma incentivam o aumento da exportação de produtos industriais brasileiros para a China. O resultado apontou para um efeito mais elástico e de magnitude maior do que o efeito verificado sobre os produtos agrícolas. Os preços relativos de exportação no modelo de produtos industriais têm uma participação menor na explicação da dinâmica dessas exportações, praticamente igual em magnitude para os produtos agrícolas, porém significativo. Tal constatação também está de acordo com os resultados obtidos por Pinto (1980), Dornbusch \& Cardoso (1980) e Braga \& Markwald (1983).

A variável quantidade exportada de bens industriais para a China $(Q I)$ tem cerca de $73 \%$ de sua variância explicada por ela mesma, sendo que $23,4 \%$ de sua variância é atribuída a choques nas variáveis renda chinesa, utilização da capacidade instalada brasileira e taxa de câmbio. Como no modelo para 
Tabela 9: Decomposição histórica da variância do erro de previsão para QI (Modelo 2).

\begin{tabular}{ccccccc}
\hline Meses & Desvio-padrão & $Q I$ & $Y$ & $U$ & $T X$ & $P R I$ \\
\hline 1 & 0,507 & 73,596 & 8,743 & 7,063 & 9,059 & 1,539 \\
2 & 0,582 & 72,658 & 7,065 & 7,143 & 9,637 & 3,497 \\
3 & 0,601 & 72,841 & 6,660 & 7,232 & 9,719 & 3,548 \\
10 & 0,609 & 72,885 & 6,484 & 7,258 & 9,736 & 3,637 \\
12 & 0,609 & 72,884 & 6,484 & 7,259 & 9,736 & 3,637 \\
\hline
\end{tabular}

Fonte: Dados da pesquisa.

commodities agrícolas, as variáveis: utilização da capacidade instalada $(Y)$ e taxa de câmbio $(T X)$ se comportam como variáveis exógenas. As variáveis renda chinesa $(Y)$ e preço relativo $(P R I)$ também têm um forte comportamento auto-regressivo, sendo que apresentam, respectivamente, cerca de $87 \%$ e $86 \%$, de suas variâncias explicadas por elas mesmas.

Na Figura 5, pode-se observar as respostas aos choques positivos de cada uma das variáveis do modelo sobre a quantidade exportada e nos períodos seguintes ao que ocorreu o choque.

A variável $Q I$ responde positivamente a um choque de $1 \%$ na renda, com resposta maior no primeiro período $(0,94 \%)$, sendo que tais choques são positivos para todos os demais períodos, desaparecendo a partir do quarto mês. A diferença para o modelo de produtos agrícolas é a intensidade do choque, neste caso dos bens industriais exportados pelo Brasil é inferior ao dos bens agrícolas exportados.

Com relação ao choque na utilização da capacidade instalada brasileira, há uma resposta negativa contemporaneamente $(-0,94 \%)$, com diminuição da magnitude dos choques até a estabilização no sexto período.

A resposta na quantidade exportada de bens industriais a um aumento de $1 \%$ na taxa de câmbio é maior no primeiro período ( $1,31 \%)$, se estabilizando somente no sétimo mês. Tal resultado reforça os resultados encontrados na análise histórica da decomposição da variância do erro de previsão, onde a taxa de câmbio teve um papel mais expressivo na explicação da quantidade exportada (cerca de $10 \%$ ).

O efeito dos preços relativos é bastante volátil, com maior intensidade durante o primeiro período $(0,32 \%)$, se estabilizando a partir do sexto período.

As respostas acumuladas de choques em cada variável sobre a quantidade exportada encontram-se sumarizadas na Figura 6. Um choque positivo de $1 \%$ na renda chinesa provoca um aumento imediato de $0,94 \%$ na quantidade exportada pelo Brasil de bens industriais, porém a elasticidade acumulada é de $1,37 \%$ e menor comparativamente ao verificado para as exportações brasileiras de produtos agrícolas. Isto reflete a preferência chinesa por commodities agrícolas na pauta de importação do Brasil na última década.

Para a utilização da capacidade instalada, há uma diminuição direta inicial das exportações com o aquecimento da economia, e a elasticidade acumulada é de $-1,50 \%$.

A taxa de câmbio tem efeito imediato significativo sobre as exportações, aumentando com o passar do tempo e se estabilizando em torno de 1,50\%, confirmando, também nesse caso, a presença do efeito da "curva J" no modelo de produtos industriais. O efeito acumulado no caso da taxa de câmbio é 


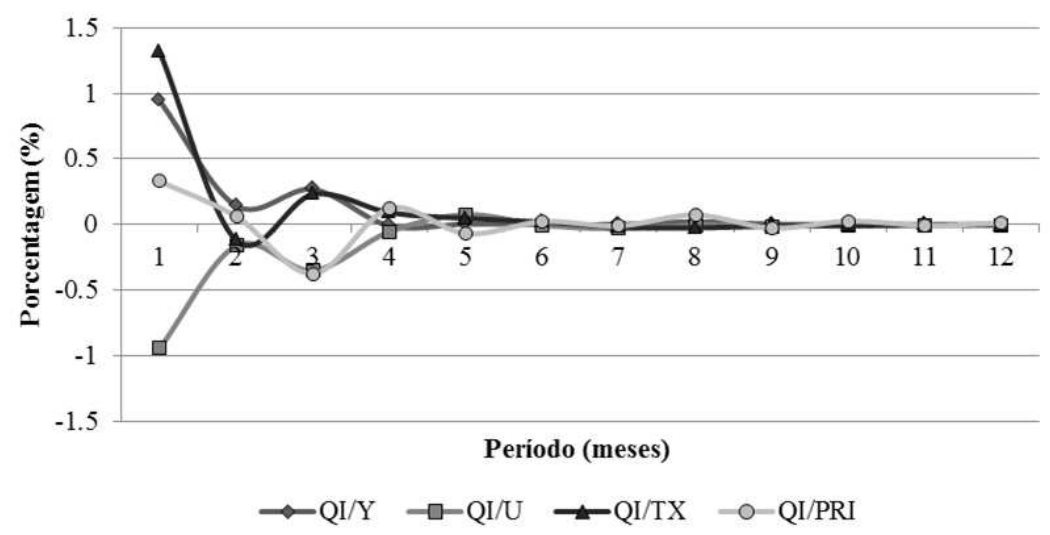

Fonte: Dados da pesquisa.

Figura 5: Função Impulso-Resposta sobre a quantidade exportada de bens industriais do Brasil para a China de um impulso nas demais variáveis (Modelo 2).

semelhante, em magnitude, ao da renda, sendo as duas principais variáveis determinantes das exportações brasileiras de produtos industriais para a China. Já a variável preço relativo, após um período de instabilidade, ela atinge o valor aproximado a $0,15 \%$.

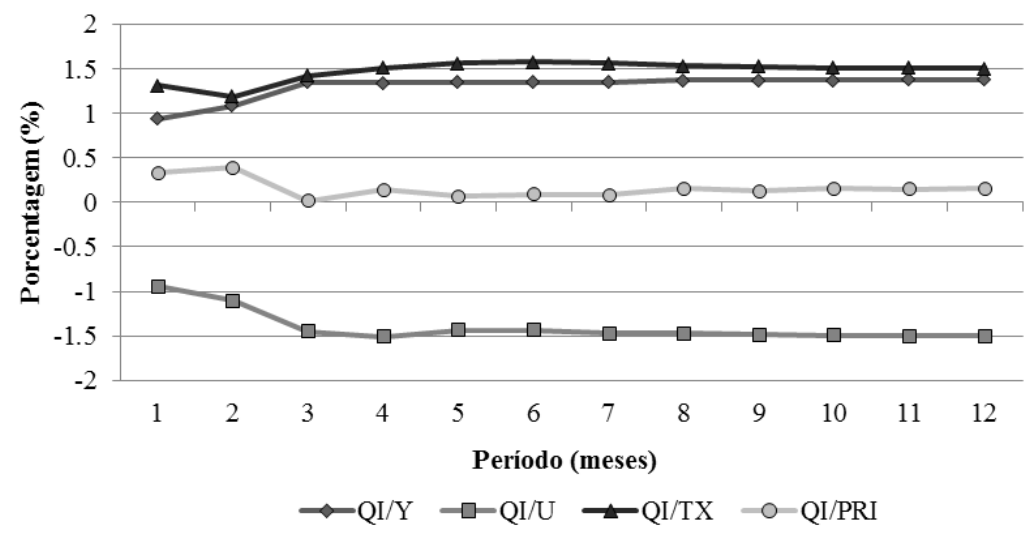

Fonte: Dados da pesquisa.

Figura 6: Evolução dos choques acumulados das exportações de bens industriais do Brasil para a China sobre as demais variáveis do modelo (Modelo 2).

\subsection{Modelo 3: Produtos minerais}

O modelo analisado foi construído seguindo a mesma especificação e com as mesmas variáveis dos modelos anteriores: $Q M, Y, Y, T X$ e PRM tomadas em primeira diferença dos logaritmos, além do vetor de correção de erros. Os sinais dos coeficientes da matriz de relações contemporâneas estão de acordo com o esperado, porém é não-significativo a $10 \%$ (significativo a $14,09 \%$ ) no 
Tabela 10: Estimativa da matriz de coeficientes de relações contemporâneas (Modelo 3).

\begin{tabular}{|c|c|c|c|}
\hline \multicolumn{2}{|c|}{ Relações Contemporâneas } & \multirow[b]{2}{*}{ Coeficientes ${ }^{*}$} & \multirow[b]{2}{*}{ Valor $t$} \\
\hline De & Sobre & & \\
\hline Renda $(Y)$ & Quant. exportada (QM) & $-1,200$ & $-4,248$ \\
\hline Util. da cap. instalada $(U)$ & Quant. exportada (QM) & 1,059 & 2,064 \\
\hline Taxa de Câmbio $(T X)$ & Quant. exportada (QM) & $-0,484$ & $-2,735$ \\
\hline Preço Relativo (PRM) & Quant. exportada (QM) & $-0,403$ & $-1,473$ \\
\hline
\end{tabular}

caso de preço relativo, da mesma forma que foi verificado no modelo para os bens agrícolas (Tabela 10).

Os demais valores mostraram-se significativos, indicando que um aumento de $1 \%$ na renda chinesa leva a um aumento de $1,20 \%$ na exportação brasileira de produtos minerais, sendo esta resposta menor, em magnitude, do que para os agrícolas, porém maior do que a dos produtos industriais. Com relação à utilização da capacidade instalada brasileira, um aumento exógeno de $1 \%$ nessa variável leva a uma redução de $1,05 \%$ na quantidade exportada para a China de bens minerais, e tal redução se assemelha a dos produtos agrícolas em grande parte por serem produtos que mantêm uma "longa memória" dos eventos, posto que o maior volume desse comércio compreende produtos estocáveis, conforme citado por Zini (1988).

Com relação à taxa de câmbio, desvalorizações na mesma incentivam o aumento da exportação de minerais para a China, porém em menor magnitude do que os efeitos das variáveis anteriores. Ademais, este efeito da taxa de câmbio sobre as exportações de produtos minerais mostrou-se, em módulo, inferior ao efeito verificado para os dois modelos anteriores (produtos agrícolas e industriais).

A variável quantidade exportada $(Q M)$ tem cerca de $75 \%$ de sua variância explicada por ela mesma, sendo que $17 \%$ de sua variância são atribuídos a choques nas variáveis renda chinesa e utilização da capacidade instalada no Brasil (Tabela 11). Já as variáveis $(Y)$ e $(T X)$ se comportam como variáveis exógenas, pois mais de $96 \%$ de suas variâncias são explicadas por choques delas próprias. As variáveis $(Y)$ e $(P R M)$ também têm um forte comportamento auto-regressivo, sendo que, respectivamente, cerca de $80 \%$ e $88 \%$, de suas variâncias são explicadas por elas mesmas.

Na Figura 7, pode-se observar as respostas aos choques positivos de cada uma das variáveis do modelo sobre a quantidade exportada de produtos minerais do Brasil para a China, contemporaneamente e nos períodos seguintes ao choque.

A variável $Q M$ responde positivamente a um choque de $1 \%$ na renda chinesa, com maior resposta no primeiro período $(1,20 \%)$, à semelhança do modelo de commodities agrícolas, alternando-se e dissipando-se a partir do sexto mês.

Ao submeter a quantidade exportada de minerais a um choque positivo de $1 \%$ na utilização da capacidade instalada brasileira há uma resposta negativa 
Tabela 11: Decomposição histórica da variância do erro de previsão para QM (Modelo 3).

\begin{tabular}{cccrccc}
\hline Meses & Desvio-padrão & \multicolumn{1}{c}{$Q M$} & \multicolumn{1}{c}{$Y$} & \multicolumn{1}{c}{$U$} & $T X$ & $P R M$ \\
\hline 1 & 0,427 & 78,445 & 9,459 & 6,257 & 4,392 & 1,447 \\
2 & 0,501 & 75,274 & 10,128 & 6,606 & 4,404 & 3,588 \\
3 & 0,522 & 74,728 & 10,544 & 6,478 & 4,570 & 3,680 \\
10 & 0,533 & 74,474 & 10,738 & 6,465 & 4,571 & 3,752 \\
12 & 0,533 & 74,474 & 10,738 & 6,465 & 4,571 & 3,752 \\
\hline
\end{tabular}

Fonte: Dados da pesquisa.

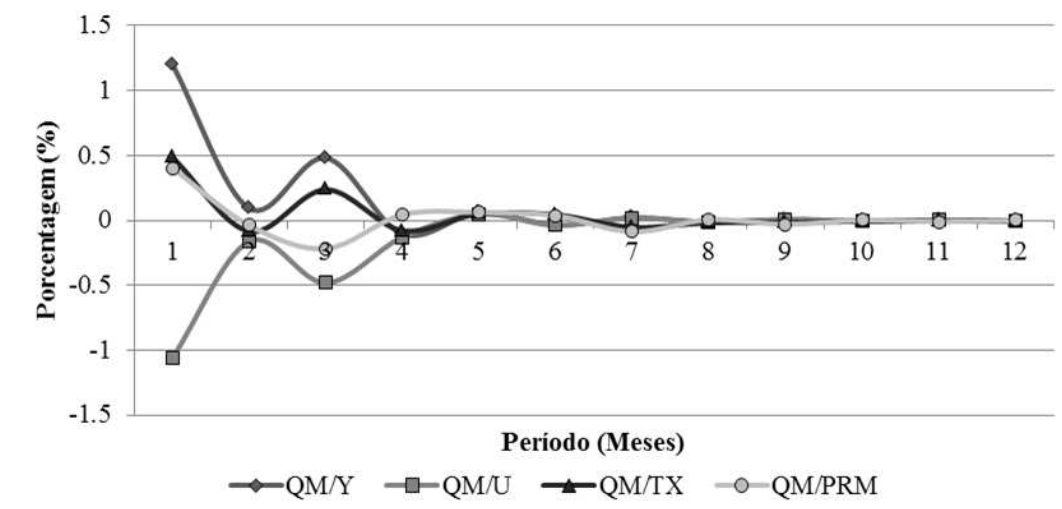

Fonte: Dados da pesquisa.

Figura 7: Função Impulso-Resposta sobre a quantidade exportada de produtos minerais do Brasil para a China de um impulso nas demais variáveis (Modelo 3).

no primeiro período de $1,05 \%$, indicando que com um aquecimento da economia no mercado interno a quantidade exportada diminui no comércio de commodities minerais. A partir do segundo período os efeitos do choque vão se dissipando, tendendo ao equilíbrio após o sétimo mês.

A resposta na quantidade exportada de um aumento de $1 \%$ na taxa de câmbio é maior contemporaneamente $(0,48 \%)$, e a partir daí o efeito se alterna de modo a oscilar, tendendo ao equilíbrio após o oitavo mês, porém a magnitude de tal efeito é inferior quando comparada a dos efeitos das demais variáveis do sistema, o que reforça os resultados obtidos na análise histórica da decomposição da variância do erro de previsão e se assemelha aos resultados obtidos para o modelo de commodities agrícolas.

O efeito do choque de $1 \%$ no preço relativo sobre a quantidade exportada de produtos minerais é maior no primeiro período, tal como verificado para os demais modelos, sendo que o efeito segue uma trajetória semelhante à do modelo de commodities agrícolas. Tal choque estabiliza-se após o oitavo mês.

As respostas acumuladas de choques em cada variável sobre a quantidade exportada de produtos minerais encontram-se resumidas na Figura 8. Dessa maneira, um choque positivo de $1 \%$ na renda chinesa provoca um aumento imediato de $1,20 \%$ na quantidade exportada, e um aumento acumulado em torno de $1,70 \%$.

Para a utilização da capacidade instalada, verifica-se que há uma diminuição direta inicial das exportações de produtos minerais à medida que ocorre 
um aquecimento da economia brasileira, e o efeito acumulado máximo é atingido num patamar menor, em torno de $-1,80 \%$.

A taxa de câmbio não tem efeito contemporâneo expressivo sobre as exportações de produtos minerais $(0,48 \%)$, e a elasticidade acumulada se estabiliza em torno de $0,55 \%$. Assim como nos demais casos analisados, pode-se verificar a presença do efeito da "curva J" no modelo de commodities minerais.

No modelo de produtos minerais, após um período de variabilidade, o preço relativo apresenta certa estabilidade em torno de $0,10 \%$; porém, como verificado na análise histórica da decomposição da variância do erro de previsão, é a variável que tem menor poder explanatório sobre a dinâmica das exportações de produtos minerais.

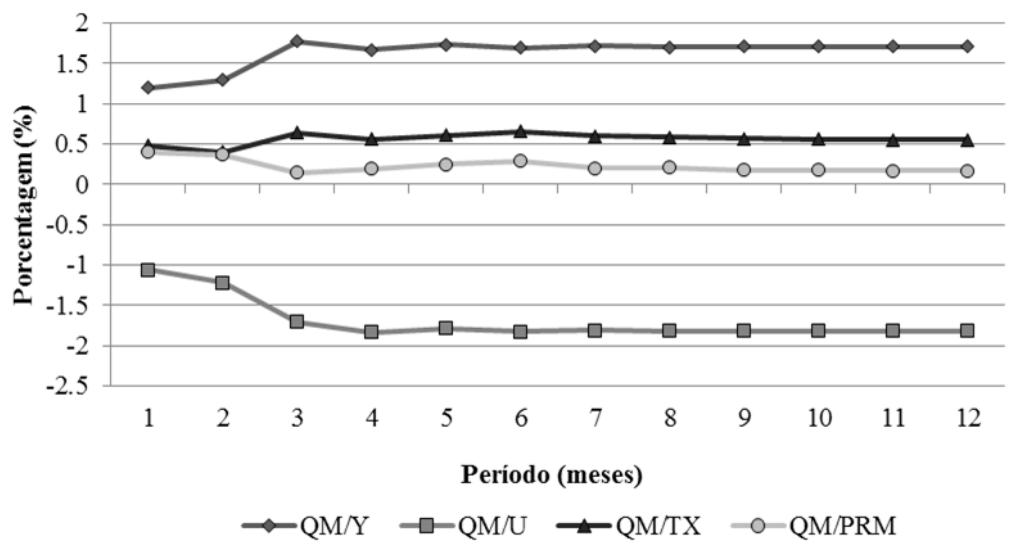

Fonte: Dados da pesquisa.

Figura 8: Evolução dos choques acumulados das exportações de produtos minerais do Brasil para a China sobre as demais variáveis do modelo (Modelo 3).

\section{Conclusões}

O comércio bilateral Brasil-China tem evoluído consideravelmente nas últimas décadas, diversos fatores condicionantes contribuíram para essa tendência. Um dos fatores de destaque é dado pela entrada da China na OMC, imprescindível para completar as reformas econômicas internas das últimas duas décadas.

Através de uma análise desagregada das principais mercadorias transacionadas entre os países pode-se verificar uma predominância de produtos industrializados, em sua maioria produtos de alto valor agregado no que se diz respeito às exportações chinesas para o Brasil. No perfil de exportação do Brasil para a China constata-se exatamente o contrário, com predominância de produtos de baixo valor agregado.

Os três modelos estimados visando avaliar as variáveis que influenciam o comércio exportador brasileiro para a China, para três categorias distintas de produtos, mostraram-se bem ajustados. Os resultados da decomposição da variância do erro de previsão para o quantum exportado pelo Brasil para a China dos produtos selecionados evidenciaram um papel importante da renda chinesa, pode-se observar que esta é responsável por cerca de $16 \%, 7 \%$ e $11 \%$ da 
variação do quantum exportado de produtos agrícolas, industriais e minerais, e a utilização da capacidade instalada do Brasil por cerca de $-10 \%,-8 \%$ e $-7 \%$, respectivamente.

A variável proxy para a renda chinesa $(Y)$ mostrou um alto poder explanatório da dinâmica das exportações brasileiras, principalmente no modelo das commodities agrícolas e minerais, respectivamente, com elasticidades contemporâneas positivas de $1,57 \%$ e $1,20 \%$, e em menor magnitude no modelo de produtos industriais, $0,94 \%$. Em todos os casos, as elasticidades acumuladas encontradas foram maiores do que as iniciais, indicando um efeito duradouro dos choques.

Tais coeficientes encontrados são bastante significativos e indicam que a demanda chinesa por exportações brasileiras é elástica em relação a variações na renda chinesa (elasticidade finita). Esse resultado é semelhante aos encontrados na literatura e vem reforçar a hipótese de que para avaliar o desempenho das exportações brasileiras é necessário especificar-se um modelo simultâneo de oferta e demanda e não apenas o de oferta.

Com relação à variável taxa de câmbio $(T X)$, esta se mostrou mais importante para explicar o modelo de exportações brasileiras de produtos industriais, com elasticidade contemporânea de $1,31 \%$, do que para os modelos de agrícolas, $0,76 \%$ e minerais, $0,48 \%$. Adicionalmente, em todos os modelos estimados, os efeitos acumulados foram maiores do que os de curto prazo, verificando a presença do efeito da "curva J" no comércio bilateral Brasil-China, com intensidade bastante menor para o caso do comércio de produtos minerais.

Os preços relativos de exportação (PR), significativos para o modelo de produtos industriais, mostraram ter um baixo poder explanatório sobre a dinâmica das exportações de commodities agrícolas e minerais. Sua elasticidade acumulada mostrou-se pouco significativa, o que é reforçado pelos resultados obtidos na análise histórica de decomposição da variância dos erros de previsão. Porém, tais coeficientes dos preços relativos indicam que a demanda externa chinesa por exportações brasileiras é elástica com relação aos preços. Pode-se concluir, no entanto, que a hipótese de que o Brasil enfrenta uma curva de demanda com elasticidade-preço infinita não é adequada. Assim, a hipótese de "país pequeno" pode ser rejeitada, e se conclui que a especificação correta, para o comércio bilateral Brasil-China, é a de produtos não substitutos perfeitos para os bens domésticos, sendo explicado por um modelo simultâneo de oferta e demanda de exportação.

A variável de utilização da capacidade instalada do Brasil $(Y)$ apresentou coeficientes consistentes para todos os modelos estimados, mostrando que tal variável conseguiu captar corretamente os efeitos da demanda interna brasileira sobre as exportações. Tal variável apresentou maior coeficiente para os produtos agrícolas, $-1,22 \%$, seguido dos produtos minerais, $-1,05 \%$ e dos produtos industriais, $-0,94 \%$. Seu efeito acumulado supera os efeitos iniciais e estabiliza-se em torno de $-1,5 \%$ a $-2 \%$ para todos os modelos, refletindo a preferência pelo mercado interno, conforme verificado na literatura.

O coeficiente da variável de utilização da capacidade instalada, além de mostrar-se estatisticamente significativo sugere que um aquecimento da demanda interna e a consequente redução do hiato do produto influenciam substancialmente a oferta de exportação, provocando uma redução nas mesmas, para todas as categorias de produtos. 
Conclusivamente, a contribuição do trabalho se deu na caracterização do comércio bilateral Brasil-China, com a ótica de analisar o mercado de commodities e de bens de maior valor agregado. Mais além, adiciona à literatura, através da utilização de um ferramental econométrico avançado, elementos para um melhor entendimento dos determinantes do comércio internacional entre estes dois países.

\section{Referências Bibliográficas}

Barros, G. S. d. C., Bacchi, M. R. P. \& Burnquist, H. L. (2002), Estimação de equações de oferta de exportação de produtos agropecuários para o Brasil (1992/2000), Texto para Discussão 865, IPEA.

Braga, H. C. \& Markwald, R. A. (1983), 'Funções de oferta e de demanda das exportações de manufaturados no brasil: estimação de um modelo simultâneo.', Pesquisa e Planejamento Econômico 13(3), 707-744.

Carvalho, A. \& Negri, J. A. D. (2002), Estimação de equações de importação e exportação de produtos agropecuários para o Brasil (1977/1998), Texto para Discussão 0698, Instituto de Pesquisa Econômica Aplicada.

Castro, A. S. d. \& Cavalcanti, M. A. F. H. (1997), Estimação de equações de exportação e importação para o Brasil - 1955/95, Texto para Discussão 469, Instituto de Pesquisa Econômica Aplicada.

Cavalcanti, M. A. F. H. \& Ribeiro, F. J. (1998), As exportações brasileiras no período 1977/96: desempenho e determinantes, Texto para discussão 545, Instituto de Pesquisa Econômica Aplicada.

Dickey, D. A., Hasza, D. P. \& Fuller, W. A. (1984), 'Testing for unit roots in seasonal time series', Journal of the American Statistical Association, American Statistical Association 79(386), 355-367.

Dickey, D. A. \& Pantula, S. G. (1987), 'Determining the order of differencing in autoregressive processes', Journal of Business and Economic Statistics 5(4), 455-461.

Dornbusch, R. \& Cardoso, E. D. (1980), 'Uma questão para as exportações brasileiras de produtos manufaturados', Revista Brasileira de Economia 34(3), 429-438.

Elliot, G., Rothenberg, T. J. \& Stock, J. H. (1996), 'Efficient tests for an autoregressive unit root', Econometrica 64(4), 813-836.

Goldstein, M. \& Khan, M. S. (1978), 'The supply and demand for exports: A simultaneous approach', The Review of Economics and Statistics 60(2), 275-86.

Hylleberg, S., Engle, R. F., Granger, C. J. \& Yoo, B. S. (1990), 'Seasonal integration and cointegration', Journal of Econometrics 44(1-2), 215-238.

Johannsen, S. (1991), 'Estimation and hypothesis testing of cointegration vectors in gaussian vector autoregressive models', Econometrica 59(6), 15511580 . 
Leamer, E. \& Stern, R. (1970), Quantitative International Economics, Allyn and Bacon, Boston.

McCorriston, S. \& MacLaren, D. (2007), 'An assessment of the economic effects of cofco', International Agricultural Trade Research Consortium, Summer Meetings, Beijing.

Meade, E. E. (1988), 'Exchange rates, adjustment, and the J-curve.', Federal Reserve Bulletin p. 633-644.

Miranda, S. H. G. (2001), Quantificação dos Efeitos das Barreiras Nãotarifárias sobre as Exportações Brasileiras de Carne Bovina, Tese de doutorado, Escola Superior de Agricultura Luiz de Queiroz, Piracicaba.

Miranda, S. H. G., Ozaki, V. A., Fonseca, R. \& Mortatti, C. M. (2007), 'Perspectives of the bilateral trade china-brazil: evaluation through a gravity model approach', International Agricultural Trade Research Consortium, Summer Meetings, Beijing.

Ng, S. \& Perron, P. (2001), 'Lag length selection and the construction of unit root tests with good size and power', Econometrica 69(6), 1519-1554.

Perron, P. \& Ng, S. (1996), 'Useful modifications to some unit root tests with dependent errors and their local asymptotic properties', Review of Economic Studies 63(3), 435-63.

Pinto, M. B. P. (1980), 'O crescimento das exportações brasileiras de manufaturados, 1954-1974', Estudos Econômicos 10(3), 101-143.

Zini, Jr., A. (1988), 'Funções de exportação e de importação para o Brasil', Pesquisa e Planejamento Econômico 18(3), 615-662. 